\title{
Non-cardiac morphological stigmata of congenital heart disease
}

\author{
BRIAN LIVESLEY* \\ M.B.(Leeds), M.R.C.P.(U.K.) \\ Department of Cardiology, King's College Hospital, London, S.E.5
}

\begin{abstract}
Summary
The recognition of morphological stigmata other than cardiac, which are now known to be associated with congenital heart disease, coupled with a familial occurrence, may permit diagnosis of specific cardiac lesions at a very early age.

Eleven such morphological associations have been reviewed.
\end{abstract}

\section{Introduction}

The presence of congenital heart disease may have contributed towards the confusion which existed in the early study of the normal anatomy and function of the heart. A patent interventricular septum allows the passage of blood between the ventricles and would have been consistent with the Galenical view that there was normally an aperture or pore between these chambers (Harvey, 1628, 1651; Moon, 1927). William Harvey was courageous enough to take a stand against this then widely accepted view and to publish his classic work in 1628, 'De Motu Cordis An Anatomical Essay', the substance of which he had known for several years. In this work he also points out the significance of the foramen ovale and the ductus arteriosus.

Since that time many varieties of congenital heart disease have, of course, been recognized. More recently scientific advances in anaesthesia and the introduction of cardiopulmonary by-pass techniques have helped the development of effective surgical treatment for many of the serious defects in which irreversible pathophysiological changes can otherwise occur. Because of this, early diagnosis is important.

Although more than 40 years separated the discovery of the stethoscope (Laennec, 1818) from the onomatopoeic description of the 'Fout-ta-ta-Rou' sounds of mitral stenosis (Duroziez, 1861), many generations of physicians have been, perhaps ex-

\footnotetext{
* Harvey Research Fellow, Department of Cardiology, King's College Hospital, London, S.E.5. Supported by a Research Grant from Pfizer Ltd, Sandwich, Kent.
}

cessively, concerned with the significance and interpretation of cardiac murmurs, especially in children. As a result of this, the 'murmur language' of the expert cardiologist has become so developed that the student may become more obsessed with the urgency of auscultation than in first making a careful study of the patient as a whole. This is unfortunate since certain non-cardiac morphological features may point towards the presence of specific congenital cardiac defects.

\section{Stigmata of congenital heart disease}

One of the earliest accounts of an abnormal bodily appearance in man is the biblical description of poly dactyly and familial gigantism which occurred in the descendants of Raphaim and included Goliath of Gath (Samuel II, 21, 18-22 and Chronicles I, 20, 5-8). The association between polydactyly and septal defects has since been reported (Ellis \& van Creveld, 1940; Wood, McDonald \& Emanuel, 1958). However, it was not until 1960 that the recognition of bodily defects became widely appreciated as assisting in the earlier diagnosis and treatment of some types of congenital heart disease. The importance of the contribution of Holt \& Oram (1960), in their description of 'Familial Heart Disease with Skeletal Manifestations', can be judged by the enthusiasm with which it has been received and the frequency with which its occurrence has been confirmed in the world literature. It has been pointed out that the radiologist can diagnose the presence of this condition even when his physician colleague may not suspect it (Poznanski, Gall \& Stern, 1970). The Holt-Oram syndrome consists essentially of the familial association of developmental abnormalities of the thumb and the radial aspect of the arm with an ostium secundum cardiac defect. Since the original description, however, other associated cardiac anomalies including ventricular septal defect and persistent ductus arteriosus have been suspected to occur in this condition and the literature has been reviewed by Silverman, Copeland \& Hurst (1970). 
The Ullrich-Turner syndrome

In 1930, Ullrich, a paediatrician, described a girl, aged 8 years, with webbing of the neck, cubitus valgus, congenital lymphangiectatic oedema, prominent ears, small mandible, ptosis, dystrophy of the nails, and hypoplastic nipples. This latter provided the clue to sexual infantilism which was added to the list by Turner (1938) before Ullrich reviewed his 20 years' experience of other cases (Ullrich, 1949). The specific cardiovascular defects associated with this condition have only recently been categorized (Nora et al., 1970). The type of cardiac defect is dependent upon whether the patient has the classical XO genotype (Ford et al., 1959), a mosaic constitution (i.e. XO/XX genotype), or simply a typical phenotype with an apparently normal genotype (i.e. either $\mathrm{XX}$ or $\mathrm{XY}$ ). The explanation of this latter apparent anomaly perhaps lies in an abnormality of the $\mathrm{X}$ chromosome and this suggestion has been supported by the hypothesis of Hecht and colleagues (1970).

When the characteristic Ullrich-Turner phenotype is associated with the more common XO genotype, then coarctation of the aorta can occur.

When $\mathrm{XO} / \mathrm{XX}$ mosaicism, $\mathrm{XX}$ or $\mathrm{XY}$ genotypes are present then pulmonary stenosis is found in association with characteristic facies, and there may be in addition an atrial septal defect (Fig. 1).

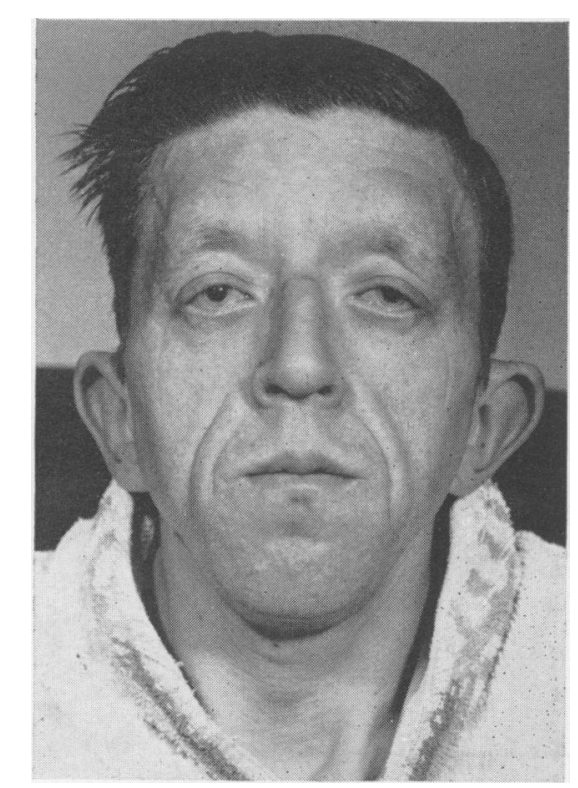

FIG. 1. Ullrich-Turner syndrome with XY genotype. The characteristic facies consists of hyperteleorism, with a prominent nose and small chin, low-set ears and ptosis. This patient has a proven secundum atrial septal defect and pulmonary stenosis.
The typical Ullrich-Turner facies shows, amongst other things, the inverted triangular appearance of hyperteleorism. This anomaly can occur alone and when familial it has been noted to be associated with congenital supravalvar aortic stenosis (Williams, Barratt-Boyes \& Lowe, 1961).

Other shoulder and hand lesions associated with congenital heart disease

Repeated dislocation of a joint, especially the shoulder, should encourage the physician to look not only for cutaneous hyperelasticity but also the presence of cardiovascular anomalies including capillary fragility. A bifid pulmonary artery and a tortuous aortic arch with a tendency of the latter to dissection has been reported in this, the EhlersDanlos syndrome (Bopp et al., 1965).

In patients with isolated arachnodactyly the incidence of atrial septal defect is high (Wood et al., 1958). Most physicians will link this digital anomaly with Marfan's syndrome, the description of which and its association with medionecrosis of the aorta is so well known that further comment here is not necessary.

Likewise, it is well recognized that in children clubbing of the fingers with central cyanosis is usually indicative of a right-to-left shunt. Clubbing of the toes with differential cyanosis of the lower half of the body, although rare because it is associated with a short life expectancy, is due to the presence of a reversed shunt across a persistent ductus with a preductal coarctation.

It has been shown in the largest single reported study of Down's syndrome (mongolism) that the incidence of congenital heart disease is almost $50 \%$. The most commonly associated cardiac anomaly is ventricular septal defect (Cullum \& Liebman, 1969).

\section{Abnormal body proportions}

In young people, coarctation of the aorta is not always associated with a clinically obvious radiofemoral pulse delay. Here, too, the collateral circulation may not be so developed as to allow the demonstration of periscapular or epigastric pulsations. In our experience in these circumstances, the significance of a parasternal systolic murmur may be appreciated only by noting the retardation of growth of the lower half of the body compared wth the upper. This abnormal length ratio implies the persistence of an impaired circulation to the lower limbs as occurs normally in the foetus (Piper, Jackson \& Livesley, 1970). In Fig. 2, the larger child had a post-ductal coarctation confirmed by cardiac catheterization (Fig. 3). On examining the family, the younger brother was found to have a systolic ejection murmur maximal at the left upper sternal edge, similar in site and character to that of the 


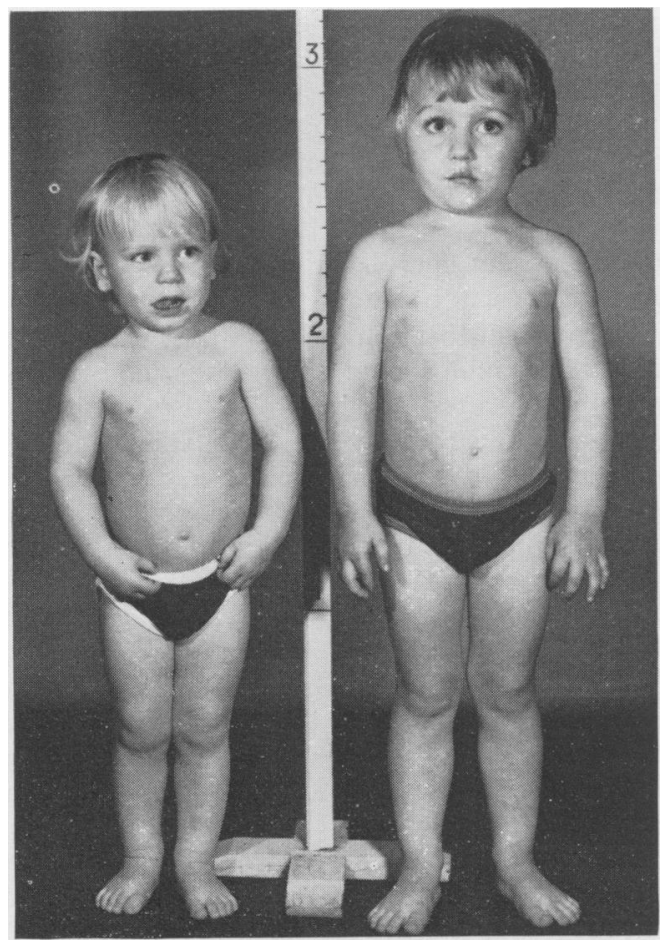

Fig. 2. The patient on the right, aged $4 \frac{1}{2}$ years, has a proven persistent ductus arteriosus and coarctation of the aorta. He has a CP/PH ratio of $1 \cdot 23$. His brother has a similar murmur and body disproportion with a $\mathrm{CP} / \mathrm{PH}$ ratio of $1 \cdot 43$.

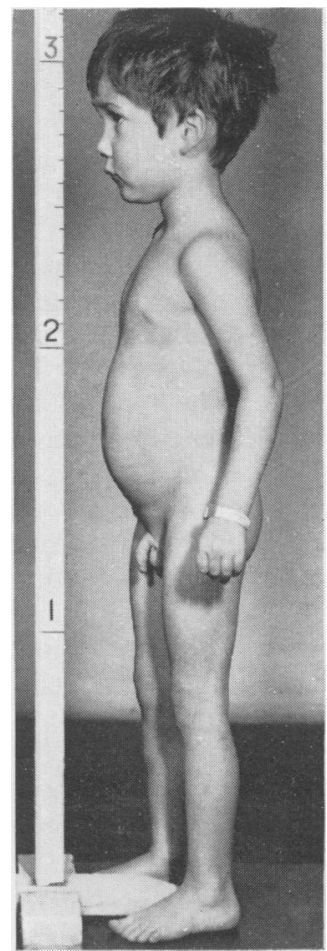

FIG. 4. The abnormal $\mathrm{CP} / \mathrm{PH}$ ratio of $1 \cdot 24$ in this patient, with a confirmed and inoperable ventricular septal defect, indicates the severity of the defect. The normal ratio for his 3 years of age is 1.05 (SD 0.1).

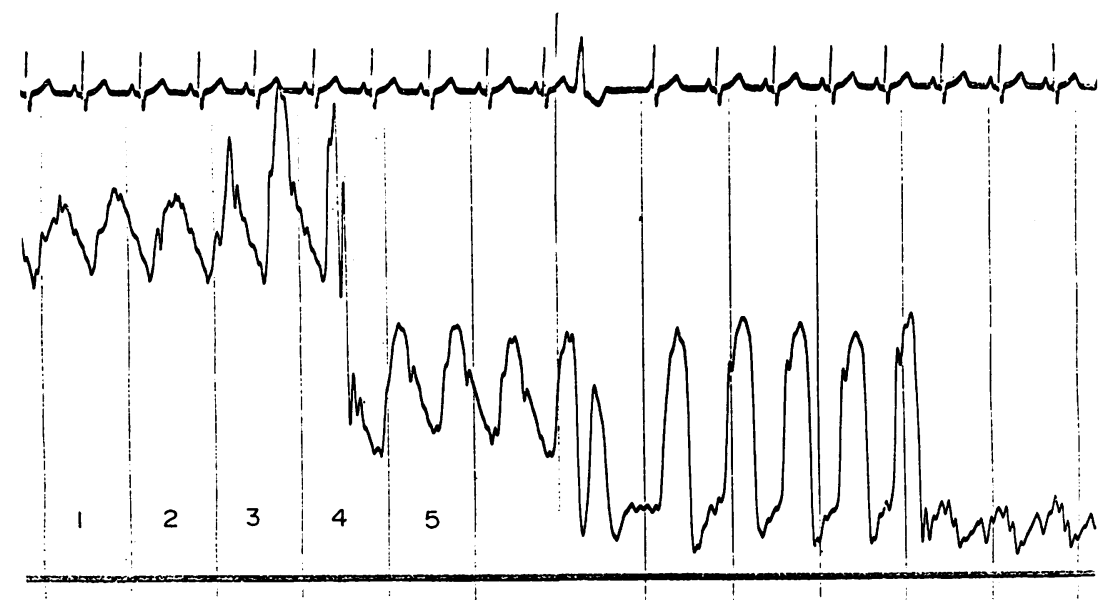

FIG. 3. Aorta-to-right atrium pressure trace. The catheter tip was withdrawn from the descending aorta (columns 1 and 2), across and proximal to a coarctation (column 3), across a persistent ductus (column 4), to the pulmonary artery (columns 5-6), right ventricle (columns 7-10) and right atrium (columns 11-12). 
murmur heard in the original patient and, it should be noted, asymptomatic. The diagnosis of coarctation in the younger child is supported by the teleradiograph, but for the present, further investigation has been deferred. In these brothers, the morphological clue to the diagnosis of a significant cardiovascular defect was the crown-pubes/pubes-heels $(\mathrm{CP} / \mathrm{PH})$ length ratio which was greater than the normal for their age. Familial coarctation of the aorta has, however, been reported previously (Taylor \& Pollock, 1953; Walker, 1934).

The patient shown in Fig. 4 had an inoperable ventricular septal defect. His body length ratio, at $1 \cdot 24$, is almost two standard deviations outside the norm for his age. This provided further clinical evidence of the serious nature of the defect prior to cardiac catheterization.

\section{Discussion}

Congenital heart disease occurs about once in every 200 live births but the actual diagnosis at the time of birth is made in only one case in 1350 single births (Smithells, 1970). The recognition that familial non-cardiac morphological stigmata can be associated with congenital heart disease may permit diagnosis of specific cardiac lesions at a stage prior to the appearance of pathognomonic cardiac physical signs. Eleven such morphological associations have been reviewed.

\section{Acknowledgments}

The author wishes to acknowledge, with gratitude, the help and stimulus which Dr Samuel Oram has given to this work. The illustrations have been provided by the Department of Medical Photography, King's College Hospital.

\section{References}

Bopp, P., Hatam, K., Bussat, P., Greder, G. \& Duchosal, P.W. (1965) Cardiovascular aspects of the Ehlers-Danlos syndrome. Circulation, 32, 602.

Cullum, L. \& Liebman, J. (1969) The association of congenital heart disease with Down's syndrome. American Journal of Cardiology, 24, 354.

Duroziez, P.L. (1861) Du retrecissement mitral pur. In: Cardiac Classics (1941) (Ed. by F. A. Willius and T. E. Keys). H. Kimpton, London.
Ellis, R.W.B. \& van Creveld, S. (1940) A syndrome characterized by ectodermal dysplasia, polydactyly, chondro-dysplasia and congenital morbus cordis. Archives of Disease in Childhood, 15, 65.

Ford, C.E., Jone, K.W., Polani, P.E., De Almeida, J.C. \& BriggS, J.H. (1959) A sex-chromosome anomaly in a case of gonadal dysgenesis (Turner's syndrome). Lancet, i, 711.

HaRvey, W. (1628) De Motu Cordis (translated by K. J. Franklin), 1957. Blackwell Scientific Publications, Oxford.

Harvey, W. (1651) First letter to P. M. Schlegel. De Circulatione Sanguinis (translated by K. J. Franklin), 1958. Blackwell Scientific Publications, Oxford.

Hecht, F., Jones, D.L., Delay, M. \& Klevit, H. (1970) Xq-Turner's syndrome: Reconsideration of hypothesis that $\mathrm{Xp}$ - causes somatic features in Turner's syndrome. Journal of Medical Genetics, 7, 1.

Holt, M. \& Oram, S. (1960). Familial heart disease with skeletal malformations. British Heart Journal, 22, 236.

LAENNEC, R.T.H. (1818) A treatise on the diseases of the chest and on mediate auscultation. In: Classics of Medicire and Surgery (Ed. by C. N. B. Camac), 1909. W. B. Saunders, London.

Moon, R.O. (1927) Growth of Our Knowledge of Heart Disease, p. 18. Longmans Green, London.

Nora, J.J., Torres, F.G., Sinha, A.K. \& McNamara, D.G. (1970). Characteristic cardiovascular anomalies of XO Turner syndrome, $\mathrm{XX}$ and $\mathrm{XY}$ phenotype and $\mathrm{XO} / \mathrm{XX}$ Turner mosaic. American Journal of Cardiology, 25, 639.

Piper, J.B., JACkson, G. \& Livesley, B. (1970). Unpublished observations.

Poznanski, A.K., Gall, J.C. \& Stern, A.M. (1970) Skeletal manifestations of the Holt-Oram syndrome. Radiology, 94, 45.

Silverman, M.E., Copeland, A.J. \& Hurst, J.W. (1970) The Holt-Oram syndrome: The long and the short of it. American Journal of Cardiology, 25, 11.

Smithells, R.W. (1970) Modern Trends in Paediatrics, Vol. 3, p. 17. Butterworths, London.

TAYlor, R.R. \& Pollock, B.E. (1953) Coarctation of the aorta in three members of a family. American Heart Journal, 45, 470.

TURNER, H.H. (1938) A syndrome of infantilism, congenital webbed neck, and cubitus valgus. Endocrinology, 23, 566.

UllRICH, O. (1949) Turner's syndrome and status BonnevieUllrich: A synthesis of animal phenogenetics and clinical observations on a typical complex of developmental anomalies. American Journal of Human Genetics, 1, 179.

WALKER, W.G. (1934) Coarctation of the aorta in father and son. New England Journal of Medicine, 211, 1192.

Williams, J.C.P., BarRatT-Boyes, B.G. \& Lowe, J.B. (1961) Supravalvular aortic stenosis. Circulation, 24, 1311.

Wood, P., McDonald, L. \& Emanuel, R. (1958) The clinical picture correlated with physiological observations in the diagnosis of congenital heart disease. Pediatric Clinics of North America, 5, 981. 